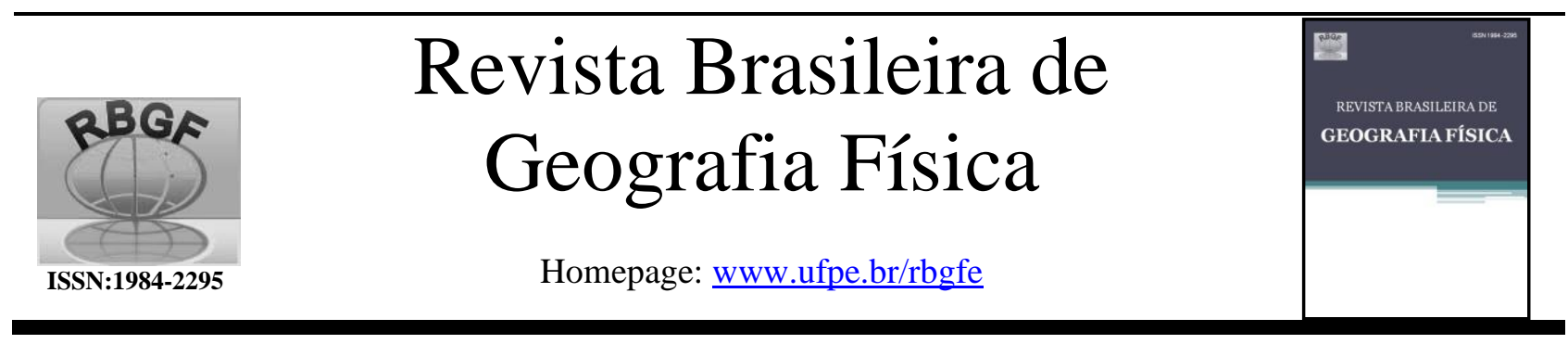

\title{
Variabilidade e Tendências das Precipitações Pluviais em Rio do Sul - SC
}

\author{
Pedro Murara ${ }^{1}$, Magaly Mendonça (in memoriam $)^{2}$
}

${ }^{1}$ Professor Adjunto do Curso de Geografia e membro permanente do PPGGEO da Universidade Federal da Fronteira Sul. Erechim-RS. E-mail: pedro.murara@uffs.edu.br. ${ }^{2}$ Professora Associada do Departamento de Geociências e membro do PPGGEO da Universidade Federal de Santa Catarina.

Artigo recebido em 21/03/2019 e aceito em 30/10/2019

\section{R E S U M O}

As inundações urbanas compreendem uma das principais problemáticas socionaturais. Conhecer a vulnerabilidade da população atingida pelas inundações é fundamental para a compreensão de ações que visem a mitigar a ocorrência desse fenômeno. Um dos primeiros passos da investigação da vulnerabilidade a inundações é conhecer a dinâmica pluvial da localidade. Nesse contexto, o presente artigo objetivou caracterizar a variabilidade das precipitações pluviais e sua relação com a ocorrência de inundações no município de Rio do Sul, localizado na mesorregião do Vale do Itajaí, no Estado de Santa Catarina. A metodologia envolveu uma intensa análise de dados de precipitações pluviais e registros de inundações, por meio de técnicas estatísticas e aplicação dos índices ClimPACT. Os resultados identificaram a estação de verão como a mais chuvosa e o outono como o período de diminuição nos totais de chuva, no entanto, as chuvas mais intensas ocorrem na estação de inverno, período em que há os maiores registros de inundações. Por fim, evidenciou-se que a região apresentou aumento nos registros dos totais pluviais e tendência à ocorrência de eventos extremos de chuvas. Palavras-chave: Precipitação Pluvial, Série histórica, Software R, ClimPACT.

\section{Variability and Trends of Rainfall Precipitation in Rio do Sul - SC}

\begin{abstract}
A B S T R A C T
Urban floods comprise one of the main socialnatural problems. Knowing the vulnerability of the population affected by floods is fundamental for understanding actions that aim to mitigate the occurrence of this phenomenon. One of the first steps in the investigation of vulnerability to floods is to know the pluvial dynamics of the locality. In this context, the present article aimed to characterize the rainfall variability and its relation with the occurrence of floods in the municipality of Rio do Sul, located in the mesoregion of the Itajaí Valley, in the State of Santa Catarina. The methodology involved an intense analysis of rainfall data and flood records, using statistical techniques and application of the ClimPACT indices. The results identified the summer season as the rainy season and autumn as the period of decline in rainfall totals, however, the most intense rains occur in the winter season, when there are the highest flood records. Finally, it was evidenced that the region presented an increase in rainfall total records and tendency to extreme rainfall events. Keywords: Rainfall, Historic Serie, Software R, ClimPACT.
\end{abstract}

\section{Introdução}

A partir da segunda metade do século XX, o Brasil passou por um processo de urbanização que resultou em cerca de $80 \%$ da população vivendo nas cidades, em meados da década de 2000 (IBGE, 2010). O crescente processo de urbanização não foi acompanhado por uma disponibilidade de infraestrutura que comportasse o grande contingente populacional que passou a viver nos espaços urbanos, resultando em uma série de problemas de ordem socionatural. Dentre os principais problemas socionaturais que ocorrem nos espaços urbanos, a falta de moradia e habitação, a ausência de saneamento básico, o Murara, $P$., Mendonça, $M$. desabastecimento de água, o uso inadequado da superfície do solo urbano, a ocupação em áreas de risco, entre vários outros passaram a se destacar como problemáticas para a população (Murara, 2016).

As cidades se tornaram lugar de maior interação efetiva entre o homem e a natureza. Ocupando pequenas parcelas do território, os espaços urbanos constituem a maior transformação da paisagem, apresentando diferentes formas de poluição do ar, água, solo e subsolo, incluindo modificações na morfologia e estrutura do ambiente urbano (Monteiro, 1976). Como resultado da fusão das ações humanas sobre a 
natureza, a cada ano há um maior número de desastres que atinge as populações urbanas. É nesse contexto que os estudiosos do clima voltaram, então, sua atenção para investigações de extremos dos elementos climáticos.

Desde a divulgação dos dados do Intergovernmental Panel on Climate Change IPCC (2012, 2014), pesquisas têm sido desenvolvidas com o objetivo de compreender os graves impactos na sociedade humana e no ambiente natural, oriundos de eventos e episódios extremos relacionados à precipitação pluvial (Armond \& Sant'anna Neto, 2017). As chuvas ganham destaque nas pesquisas devido a sua relação intrínseca com desastres por enchentes e inundações.

Dessa forma, faz-se necessário, cada vez mais, compreender a variabilidade das precipitações pluviais, dado que, quando de sua maior intensidade nos espaços urbanos, diferentes setores da economia e da sociedade têm grandes danos e perdas no que confere aos transtornos relativos à circulação de transportes e pessoas, à comunicação, às atividades serviços, e ainda, aos problemas vinculados à saúde da população.

Estudos e pesquisas são desenvolvidos a cada ano, e novos avanços são efetuados na compreensão da dinâmica atmosférica, assim como nas abordagens para as análises em escalas regional e local. Embora essas investigações possibilitem uma melhor compreensão dos estudos sobre mudanças e variabilidades em condições extremas de temperatura e precipitação, deve-se reconhecer que ainda são escassas para a dimensão do território nacional brasileiro.

Uma das principais razões para isso é dada pela identificação de eventos extremos que requerem séries temporais precisas, completas e espacialmente coerentes em escala diária. Entretanto, os dados diários estão entre as principais dificuldades àqueles dispostos a realizar uma análise mais detalhada (Marengo et al., 2009).

No Brasil e em outros países da América do Sul, as maiores dificuldades estão relacionadas à ausência de estações de longo prazo e, também, à baixa qualidade das séries de dados. Reconhece-se que variações de longo prazo em séries temporais podem ser identificadas não apenas por mudanças do tempo e do clima, "mas também por mudanças

\footnotetext{
$1 \mathrm{O}$ estudo apresentado é baseado na pesquisa de tese de Doutorado do referido autor, finalizado no ano de 2016, sob a orientação da Prof. ${ }^{a}$ Dr. ${ }^{a}$ Magaly Mendonça, que faleceu um mês antes da defesa de tese. Por esse motivo, seu nome é apresentado no artigo como uma homenagem e, ao mesmo tempo, como coautoria da pesquisa desenvolvida. Neste artigo, optei ainda por enfatizar a metodologia de análise de dados, Murara, $P$., Mendonça, $M$.
}

na localização das estações, instrumentos, fórmulas utilizadas para calcular os meios, observando as práticas e ambiente da estação" (Acquaotta \& Fratianni, 2014, p. 20). Portanto, o primeiro passo para uma análise climática é um rigoroso controle de qualidade e avaliação da homogeneidade do conjunto de dados.

Diante desses desafios, o presente artigo objetivou caracterizar a variabilidade das precipitações pluviais para compreender a dinâmica das chuvas e sua relação com a ocorrência de inundações no município de Rio do Sul, localizado na mesorregião do Vale do Itajaí, no Estado de Santa Catarina ${ }^{1}$.

\section{Área de Estudo}

A literatura científica apresenta pesquisas sobre os recorrentes episódios de inundações verificados nos municípios do Vale do Itajaí. Os estudos desenvolvidos por Frank (1995, 1997, 2007), Vibrans (2003), Fraga (2005), Herrmann et al. (2007), Frank e Sevegnani (2009), Lapolli (2013), e Herrmann (2014) avançaram na compreensão e nos apontamentos dos motivos para os constantes episódios de inundações que atingem a população regional.

Desde 2000, o Grupo de Estudos em Desastres Socio Naturais - GEDN, da Universidade Federal de Santa Catarina (UFSC), realiza pesquisas sobre os diversos desastres que ocorrem no Estado. O último levantamento resultou no Atlas de Desastres Naturais do Estado de Santa Catarina (2014), o qual apresenta a mesorregião do Vale do Itajaí com a maior frequência de episódios de inundações (graduais e bruscas) no período de 1980 a 2014.

O município de Rio do Sul possui área de pouco mais de $260 \mathrm{~km} 2$ e dista aproximadamente $200 \mathrm{~km}$ de Florianópolis, a capital do Estado. Posicionado entre a Serra do Mar e a Serra Geral, $27^{\circ} 12^{\prime}$ 'sul e $49^{\circ} 38^{\prime}$ oeste. Pela sua localização na porção central e a montante da bacia hidrográfica do Rio Itajaí-Açu, apresenta em sua área urbana a confluência dos rios Itajaí do Sul e Itajaí do Oeste, convergência que dá origem ao Rio Itajaí-Açu, que percorre o restante da bacia hidrográfica e deságua no Oceano Atlântico, entre as cidades de Itajaí e Navegantes (Figura 1). Por esse motivo, a seleção desse município como área de estudo se faz

homogeneização de séries históricas e aplicação de índices do ClimPACT que foi desenvolvido na minha pesquisa de Doutorado como parte do estágio sanduíche que realizei na Università degli Studi di Torino (Itália) sob a orientação da Professora e amiga, Dr. ${ }^{\text {a }}$ Simona Fratianni 
estratégica, visto que, do ponto de vista da localização geográfica, Rio do Sul, e mais especificamente a sua área urbana, está sujeita à recepção das águas pluviais e fluviais que ocorrem na porção a montante da bacia hidrográfica, caracterizando essa área como a primeira atingida quando da ocorrência de episódios de inundações (Murara, 2016).

No município de Rio do Sul se evidencia uma ocupação do espaço em que o homem procurou adaptar a natureza às suas necessidades na busca pelo progresso e pelo desenvolvimento. Dessa forma, os afluentes do rio Itajaí-Açu tiveram, principalmente, suas margens ocupadas ao longo dos anos. As planícies aluviais e os fundos de vale constituíram as principais localidades para o processo de estruturação das cidades, bem como para uso agrícola.

No entanto, devido a sua feição geomorfológica em forma de vale aberto, com configurações de estreitas planícies aluviais, associada às chuvas abundantes na região - do tipo climático temperado (subtropical) úmido, resultando em precipitações bem distribuídas ao longo do ano - a ocupação humana e o uso do solo ao longo da bacia hidrográfica do Rio Itajaí estão fadados aos processos de cheias e inundações (Frank, 1995, 1997, 2007; Vibrans, 2003; Fraga, 2005, Herrmann et al., 2007; Frank e Sevegnani, 2009; Lapolli, 2013; Herrmann, 2014; Murara, 2016).

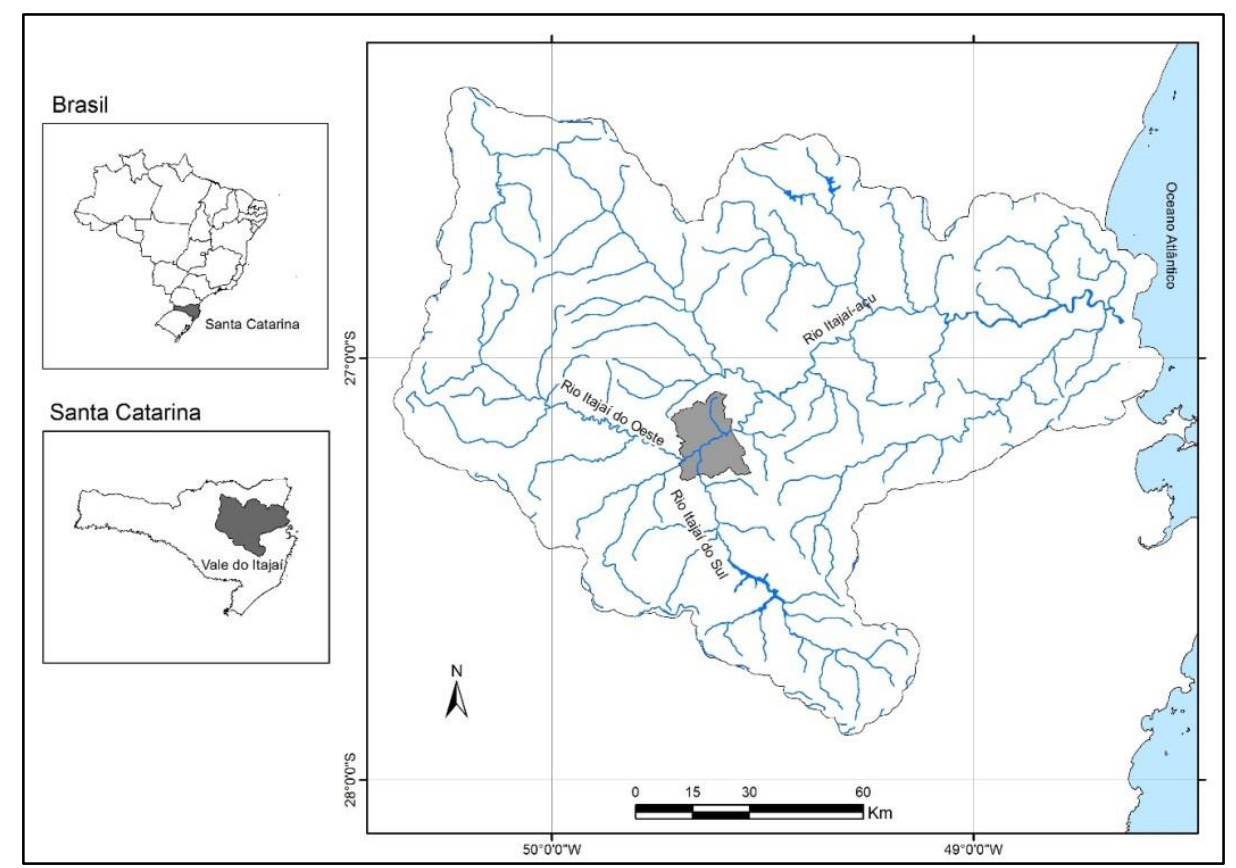

Figura 1. Localização do município de Rio do Sul na Bacia Hidrográfica do Rio Itajaí.

Um levantamento sobre a dinâmica climática e a variabilidade das precipitações no município de Rio do Sul foi efetuado por Murara e Ikefuti (2017), abrangendo a escala local da área de estudo. No referido trabalho, os autores identificaram os meses de janeiro, fevereiro e outubro como os de maiores registros de precipitação, assim como o trimestre abril-maiojunho aparece com os menores registros de chuva.

Embora o município de Rio do Sul se encontre em uma zona identificada pela homogeneidade na distribuição das precipitações pluviais, na qual a mesorregião do Vale do Itajaí é caracterizada pelo clima temperado (subtropical) subquente, superúmido e sem seca (Nimer, 1971), novos estudos têm apresentado uma diferença de cerca de $80 \mathrm{~mm}$ entre o mês mais chuvoso e o menos chuvoso, em algumas localidades (Murara e Ikefuti, 2017).

\section{[...] "no que se refere à pluviometria", com medias anuais variando entre $1.250 \mathrm{a} 2.000 \mathrm{~mm}$, destacando os meses de agosto, setembro e outubro para concentração máxima da precipitação. Em contrapartida, os meses de abril, maio, junho e julho são identificados como os meses menos chuvosos. (Nimer, 1971).}

Outros autores como Monteiro (2001), Nery (2005) e Grimm (2009) identificaram anomalias de precipitação em algumas localidades da região Sul do Brasil, associando esses resultados, principalmente, ao fenômeno ENOS e à situação geográfica na qual se localiza a região Sul, cujos efeitos topográficos (barreiras, vales e serras) se associam na distribuição diferenciada das chuvas na região (Grimm, 2009). 


\section{Procedimentos Metodológicos}

Para o estudo sobre a dinâmica climática do município de Rio do Sul, realizou-se pesquisa bibliográfica com base nos trabalhos de Monteiro (1968), Nimer (1971), Monteiro \& Furtado (1995), Frank (1999; 2003), Fraga (2005), Monteiro (2001; 2007), Rodrigues et al. (2004), Mendonça (2002), Mittersteins \& Severo (2007), Grimm (2009), Frank \& Savegnani (2009), Herrmann (2014), Monteiro \& Mendonça (2014), Hillesheim \& Neves (2015), Murara (2016) e Murara \& Ikefut (2017).

Para a compreensão da dinâmica das chuvas, fez-se necessário, inicialmente, identificar aumento, estabilidade ou diminuição das precipitações pluviais, ou seja, compreender a variabilidade das chuvas, fator importante no processo que envolve as inundações. Nessa etapa, efetuou-se levantamento de dados pluviométricos das sub-bacias do Rio Itajaí. Ou seja, considerouse os dados de precipitação pluvial das sub-bacias do Itajaí do Oeste e Sul, uma vez que o município de Rio do Sul se localiza na confluência dos rios, ponto de intersecção das sub-bacias, dando, ali, origem ao Rio Itajaí-Açu (Figura 2). Portanto, consideramos toda a precipitação que ocorre a montante do município de Rio do Sul, uma vez que a área urbana do município se constitui como exutório no respectivo estudo.

Os dados utilizados foram coletados em escala diária a partir de duas instituições: i) Agência Nacional de Águas (ANA), que disponibiliza dados de precipitação pluvial gratuitamente por meio da sua página na internet; ii) Centro de Informações de Recursos Ambientais e de Hidrometeorologia de Santa Catarina (EPAGRI/CIRAM), que possui estações distribuídas pelo Estado.

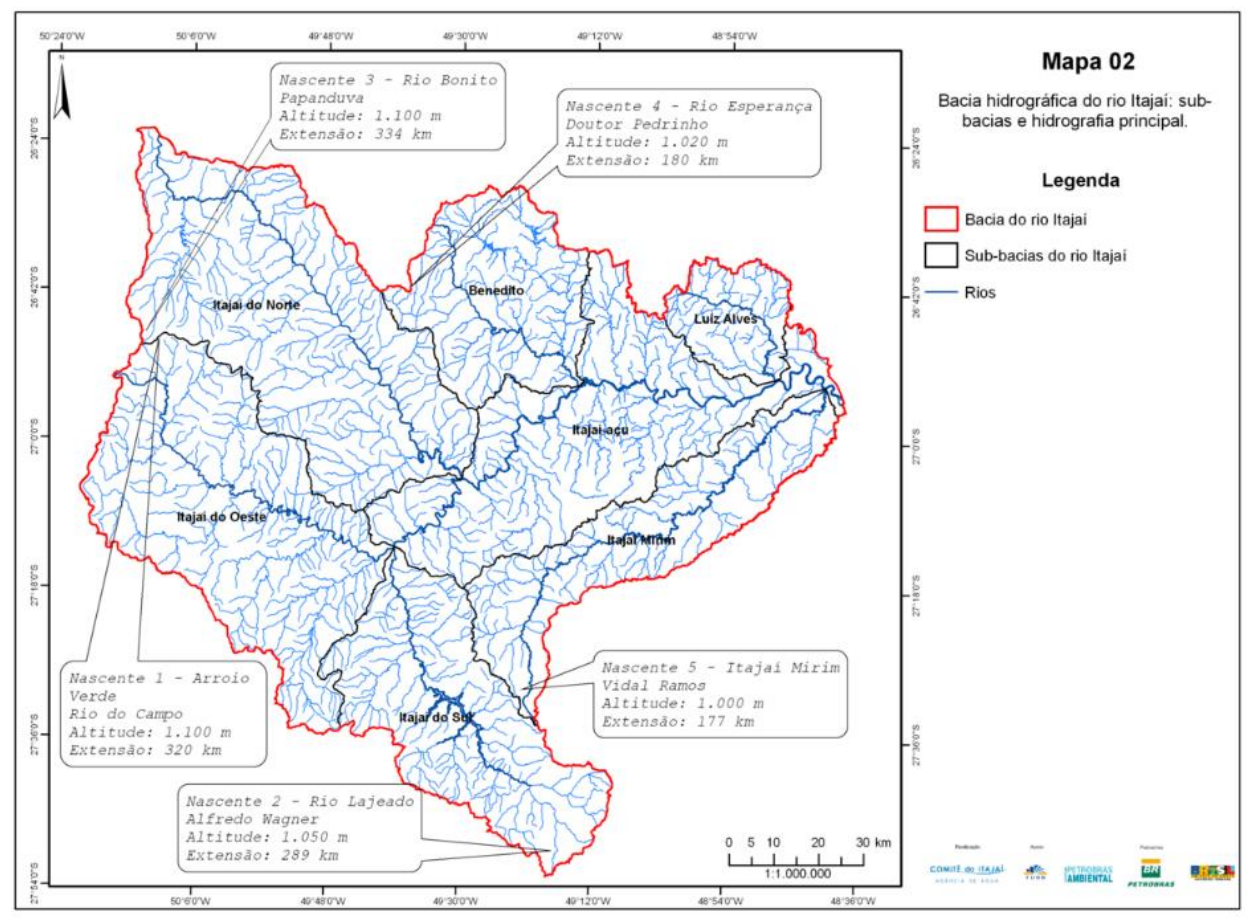

Figura 2. Bacia e sub-bacias hidrográficas do rio Itajaí.

Fonte: Comitê do Itajaí, 2013.

Foram identificadas, incialmente, 32 estações pluviométricas, sendo que apenas 24 estações apresentam dados disponíveis para análise na escala diária. As outras 08 estações não possuem dados disponíveis em quaisquer escalas (diária, mensal ou anual). Após essa primeira filtragem das estações, os dados foram analisados por meio de controle para verificar falhas (lacunas) nas séries históricas, de acordo com metodologia utilizada por Acquaotta \& Fratianni (2014).

A análise do controle de dados envolve, em um primeiro momento, pesquisa histórica. Logo, realizou-se contato com a ANA e com a EPAGRI/CIRAM para verificar a origem das ausências de dados nas séries históricas. Segundo informações e laudos técnicos, algumas estações passaram, ao longo dos anos, por mudanças na sua localidade, assim como alterações nos aparelhos de coleta de dados. Ainda, algumas estações deixaram de funcionar e outras passaram a coletar dados na mesma localidade, interferindo, portanto, na série histórica.

Para as 24 estações pluviométricas que possuíam dados, efetuou-se análise de consistência 
para identificação de possíveis erros. Foram consideradas apenas as séries históricas nas quais os valores mensais acumulados apresentavam mais de $80 \%$ dos dados diários disponíveis (Klein Tank et al., 2002; Sneyers, 1990). Para os valores anuais foram consideradas as séries com mais de $96 \%$ de dados diários (Aquaotta et al., 2009; Klein Tank \& Konnen, 2003; Venema, et al., 2012). Em seguida, para os municípios que possuíssem duas ou mais estações, analisou-se a possibilidade de sobreposição de suas séries de dados. Esse procedimento objetivou a reconstrução de séries para uma análise de maior temporalidade.

A partir das séries históricas disponíveis, 07 municípios apresentavam duas ou mais estações pluviométricas, possibilitando a reconstrução da série de dados. A avaliação também considerou a sobreposição cuja diferença de elevação entre os pontos comparados não fosse superior a $200 \mathrm{~m}$ e a distância entre os pontos não ultrapassasse o raio de 20km (Biancotti et al., 2005; Isota et al., 2013). Dessa forma, apenas dois municípios, Agrolândia e Rio do Sul, justificaram esse procedimento.

A fim de possibilitar uma comparação direta, todos os valores que estavam ausentes em uma das séries de dados também foram definidos como ausentes na sua contraparte antes da execução das análises estatísticas serem calculadas. Além disso, os valores diários de precipitação de menos de $1 \mathrm{~mm}$ das séries não foram considerados, para evitar que um conjunto de valores com pequenas alterações reflita na precisão de medição e análise (Wang et al., 2010; Acquaotta et al., 2015a).

As estações com período de sobreposição foram analisadas pela metodologia de Comparação das Chuvas - Co:Rain (Guenzi et al., 2015). Essa metodologia mostra a descontinuidade entre os pares de séries, destacando não só a diferença média entre os valores diários, mas analisando como foram registradas classes diversas de eventos chuvosos, fracos, pesados ou extremos (Acquaotta et al., 2015b).

O Co:Rain utiliza testes não paramétricos aplicados aos valores diários para avaliar as relações preliminares entre os pares de séries. $\mathrm{O}$ erro médio quadrático é utilizado para identificar a diferença média entre as séries, enquanto o método de Spearman é utilizado para avaliar o coeficiente de correlação. O teste de Kolmogorov-Smirnov é aplicado para determinar se dois conjuntos de dados poderiam ter vindo da mesma distribuição, enquanto o teste de pontuação de Wilcoxon é considerado para determinar se duas amostras têm medianas idênticas. Utiliza-se um nível de significância $\mathrm{p}=5 \%$ para todos os testes. Dessa análise, apenas na estação de Rio do Sul foi possível a união das séries temporais que resultou em uma única série de dados com recorte temporal de 1941 a 2015.

Efetuados os procedimentos anteriores, as estações pluviométricas com dados disponíveis foram mapeadas e localizadas conforme a Figura 3. Foram utilizadas 14 estações pluviométricas, no entanto, devido ao período temporal diferenciado entre as estações, optou-se pela análise em duas etapas. Destaca-se que foram consideradas e utilizadas 03 estações que extrapolam os limites da bacia hidrográfica para melhor consistência nos resultados.

Para a análise das precipitações que ocorrem nas sub-bacias, e como consequência do maior número de estações, foi selecionado o período de 1983 a 2015, compreendendo 33 anos. Efetuado o processo de homogeneização de dados, foram criados tabelas e gráficos que auxiliaram na compreensão da dinâmica das precipitações pluviais nas escalas diária, mensal, sazonal e anual.

Após esse primeiro panorama temporal sobre a dinâmica das chuvas que ocorre em Rio do Sul e na porção a montante das suas sub-bacias, passou-se a uma segunda etapa da investigação, pautada na compreensão das tendências das precipitações pluviais. Sendo assim, efetuou-se o cálculo do índice de precipitação para compreender as quantidades de chuvas que ocorrem ao longo dos dias.

Utilizando-se de dados diários, foram somados os totais de precipitação mensais e divididos pelo número de dias de chuva que ocorrem no respectivo mês. Essa divisão da quantidade de chuva pelo número de dias de chuva gera um valor que permite identificar, no mês ou na estação do ano, como se deu a distribuição das precipitações pluviais. Para a análise das estações do ano, considerou-se como verão os meses de dezembro, janeiro e fevereiro, de modo que, março, abril e maio são identificados como outono, seguidos pelos meses de junho, julho e agosto como a estação de inverno e setembro, outubro e novembro como respectivos à primavera. 


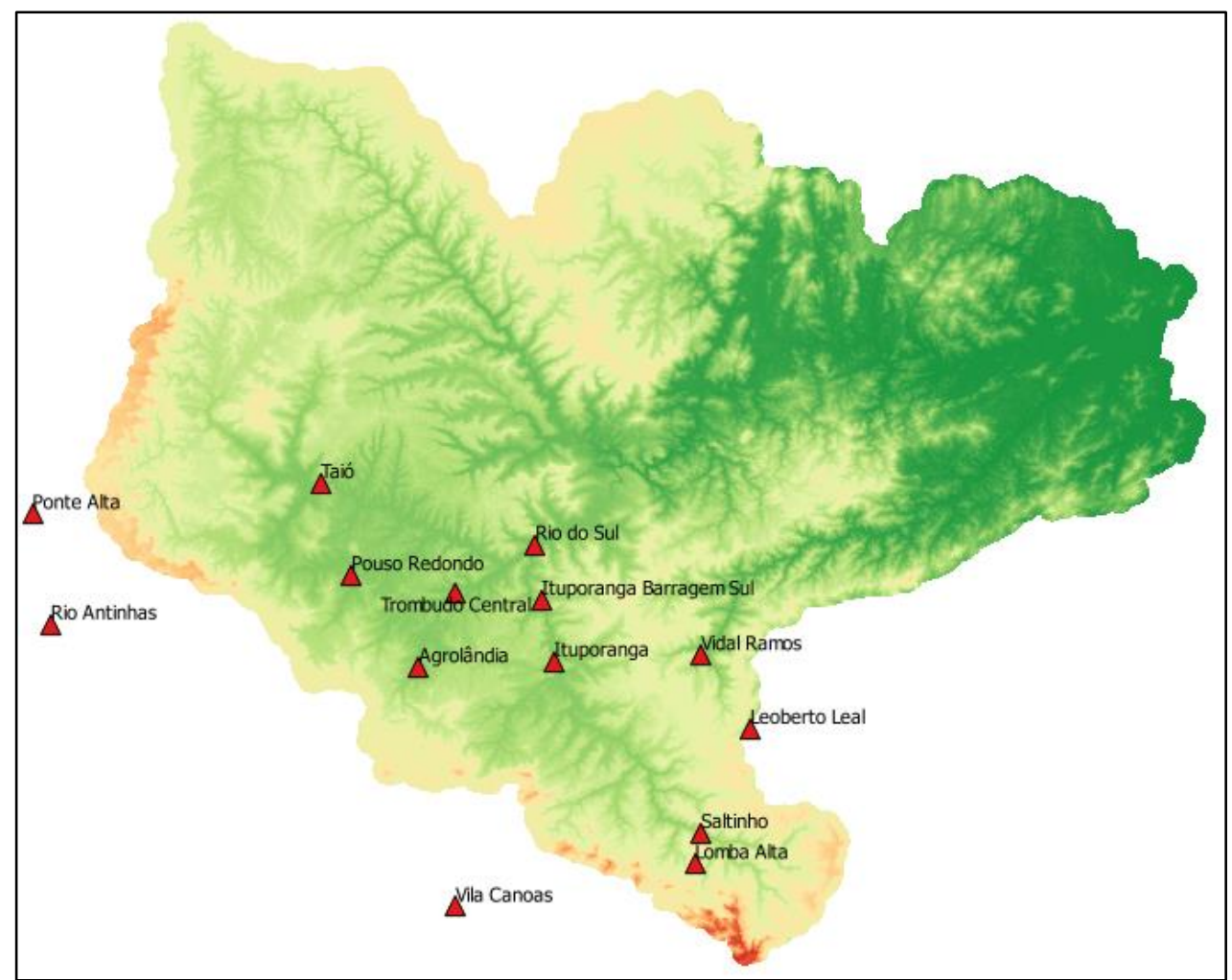

Figura 3. Localização das estações pluviométricas utilizadas.

Fonte: ANA e EPAGRI, 2016.

Por fim, os dados diários de precipitação foram analisados por meio do software ClimPACT. Trata-se de um software escrito em programação R, uma linguagem e ambiente para computação estatística, disponível como software livre ${ }^{2}$. O ClimPACT é baseado no software RClimdex, desenvolvido pela Commission for Climatology/Variability and predictability of the ocean-atmosphere

system

(CCL/CLIVAR/JCOMM), equipe de especialistas da Organização Meteorológica Mundial (OMM) sobre Detecção de Mudanças Climáticas e Índices (ETCCDI), que possibilita computar 34 índices climáticos a partir de um rigoroso controle de Quadro 1. Índice utilizados pelo ClimPACT

\begin{tabular}{|l|l|l|}
\hline Índice & Nome do índice & Definição \\
\hline CDD & Dias secos consecutivos & $\begin{array}{l}\text { Número máximo de dias consecutivos com precipitação < } \\
\text { um milímetro }\end{array}$ \\
\hline CWD & Dias úmidos consecutivos & $\begin{array}{l}\text { O número máximo de dias consecutivos quando a } \\
\text { precipitação } \geq 1 \mathrm{~mm}\end{array}$ \\
\hline Rx1dia & Índice simples de intensidade diária & $\begin{array}{l}\text { Proporção de precipitação total anual para o número de dias } \\
\text { chuvosos }(>1 \mathrm{~mm})\end{array}$ \\
\hline Rx5dias & Dias consecutivos de precipitação & Precipitação mensal máxima em 1 dia \\
\hline Rx8dias & Dias consecutivos de precipitação & Precipitação mensal máxima em 5 dias consecutivos \\
\hline PRCTOT & Total anual de dias de chuva & Precipitação mensal máxima em 8 dias consecutivos \\
\hline R10mm & Número de dias chuvoso & Precipitação $\geq 1 \mathrm{~mm}$ \\
\hline
\end{tabular}

${ }^{2}$ Sob os termos da GNU - General Public License da Free Software Foundation em forma de código-fonte (ver http://www.r-project.org/).

Murara, $P$., Mendonça, $M$. qualidade de dados. A elaboração de índices de tendências de mudanças climáticas de uma determinada região/localidade funciona como ferramenta imprescindível para a compreensão do fenômeno das mudanças climáticas globais.

Sob o enfoque das precipitações pluviais, foram utilizados 08 índices climáticos. Por meio da utilização dos índices climáticos selecionados (Quadro 1) foi possível detectar tendências nas precipitações pluviais para as 14 estações utilizadas. 


\begin{tabular}{|l|l|l|}
\hline R20mm & Número de dias chuvoso & Contagem anual de dias em com precipitação $\geq 20 \mathrm{~mm} /$ dia \\
\hline R95p & Extremo de precipitação & Total anual de precipitação com percentil $\geq 95 \mathrm{~mm}$ \\
\hline R99p & Muito extremo de precipitação & Total anual de precipitação com percentil $\geq 99 \mathrm{~mm}$ \\
\hline
\end{tabular}

Além disso, os dados referentes às cotas de inundações foram coletados junto à Defesa Civil Municipal de Rio do Sul. Utilizou-se, ainda, os dados de inundações do Centro de Operação do Sistema de Alerta (CEOPS), coordenado pela Universidade Regional de Blumenau, assim como o banco de dados dos registros de inundações do Grupo de Estudo de Desastres Socio Naturais GEDN da Universidade Federal de Santa Catarina (UFSC), para corroborar a tabela de registros.

\section{Resultados}

Pelo escopo dado ao presente artigo, não serão aqui descritos, detalhadamente, os dados referentes à variabilidade mensal e anual das precipitações. Tais informações já foram discutidas em Murara \& Ikefut (2017). Assim, parte-se para a análise da sazonalidade das precipitações pluviais conforme Figura 4.

Evidencia-se o verão (média de $154,79 \mathrm{~mm}$ ) como a estação mais chuvosa, seguido pela proximidade nos registros pluviais da estação de inverno (média de 150,90 mm). A primavera apresenta valores inferiores a $150 \mathrm{~mm}$ (média de $141,49 \mathrm{~mm}$ ) e o outono, por sua vez, apresenta os menores registros médios de precipitação pluvial $(122,84 \mathrm{~mm})$.

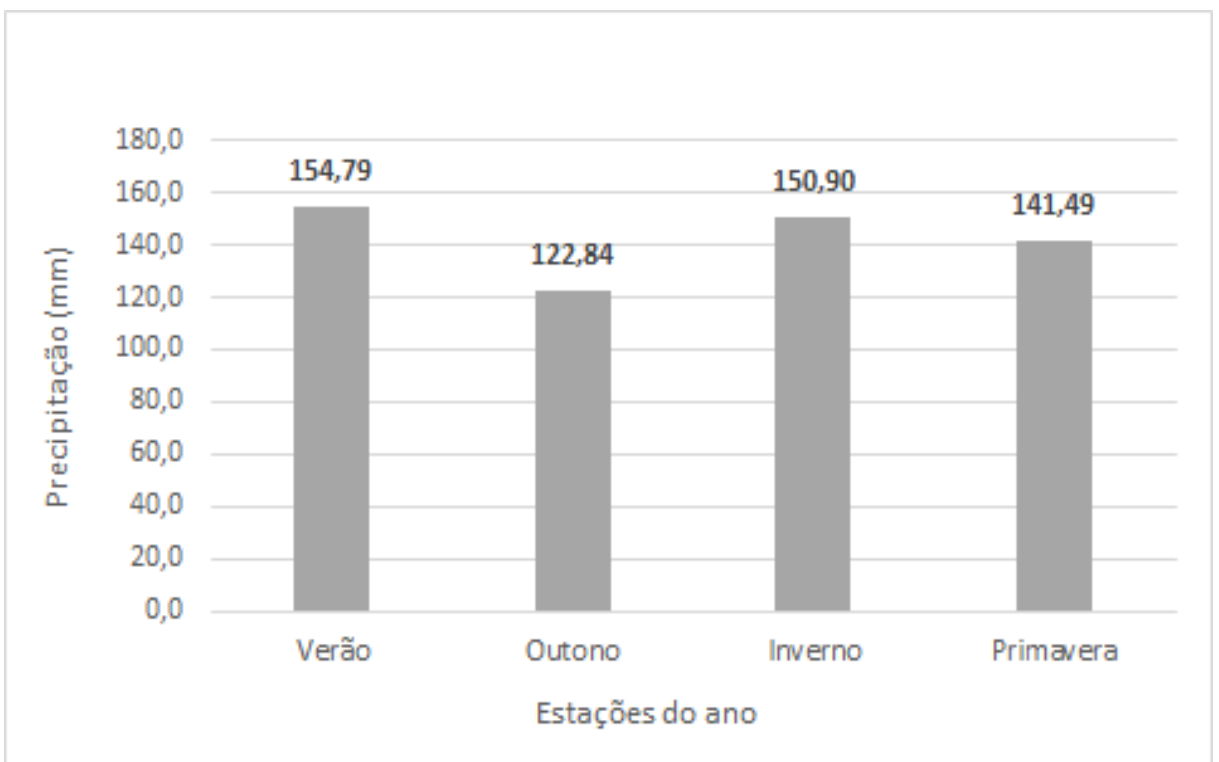

Figura 4. Média das precipitações pluviais por estação do ano.

No entanto, embora a estação de verão seja a mais chuvosa, o índice de precipitação é maior na estação de inverno $(15,60)$, conforme Figura 5. Esse resultado revela que a quantidade de chuva no inverno ocorre em um período de tempo menor, logo, um alto índice quando comparado com as demais estações do ano, sugerindo a ocorrência de chuvas concentradas e, portanto, indicando esse período como o de maior possibilidade de eventos de inundações.

Os demais índices seguem com valores de 14,05 para a estação de primavera, 13,26 para o verão, e o outono com o menor índice de precipitação, registrando 12,76. Ademais, esse resultado, em certa medida, vai de encontro com a bibliografia que trata da distribuição uniforme das chuvas ao longo do ano para a região Sul do Brasil (Nimer, 1971), ou melhor, quando se tratam de especificidades locais, as realidades não apresentam a mesma homogeneidade como na escala regional. Dessa forma, os resultados acima descritos vão ao encontro de estudos mais recentes (Monteiro, 2001; Nery, 2005; Grimm, 2009; Murara \& Ikefut, 2017), evidenciando, em escala regional e local, a diferenciação da distribuição das precipitações pluviais para a região Sul do Brasil. 


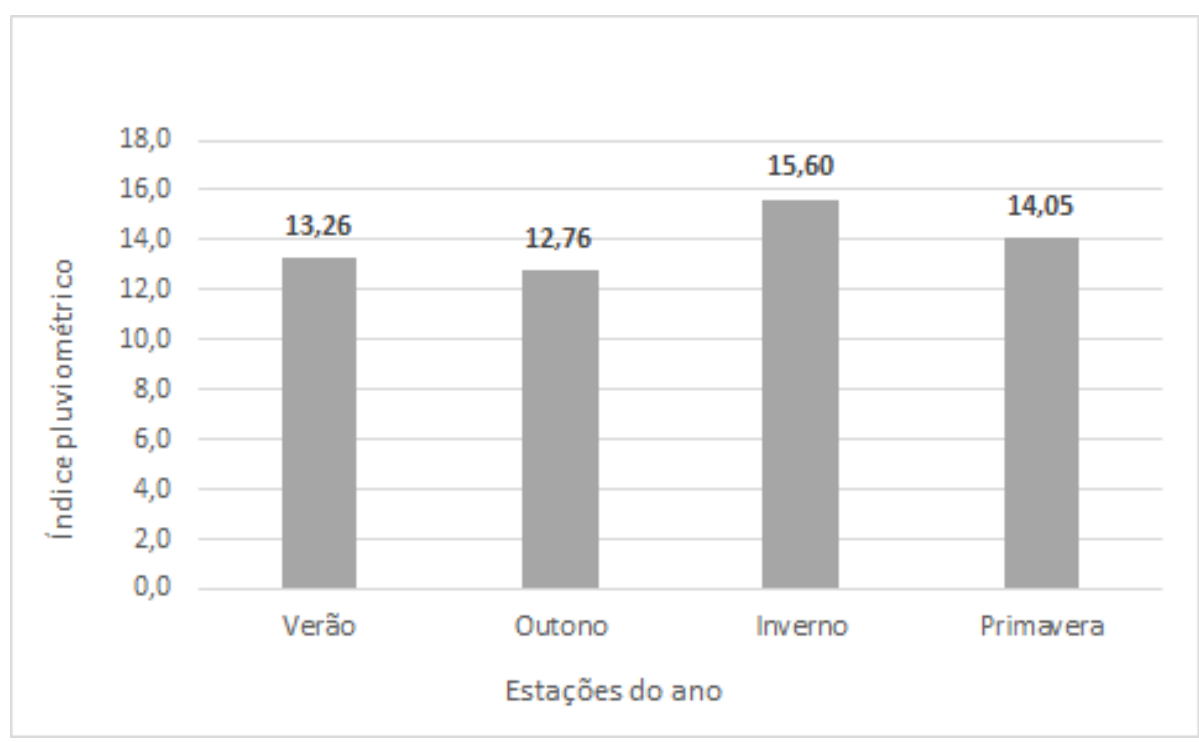

Figura 5. Índice de precipitação pluvial por estação do ano.

De acordo com os registros de inundações (Tabela 1), é na estação de inverno que há maior frequência, totalizando $42 \%$ das ocorrências, seguido pela estação de outono (26\%), primavera (23\%) e verão (10\%). Conforme já apresentado na Figura 5, a estação de inverno é caracterizada pelos maiores índices pluviométricos, sugerindo-a como período propício para a ocorrência de eventos de inundações.

Diante dos resultados apresentados, partiuse para a aplicação dos índices de precipitação utilizados pelo ClimPACT com o objetivo de acurácia na conclusão de possíveis alterações e/ou variabilidade nos registros de precipitação das estações pluviométricas localizadas nas sub-bacias a montante do município de Rio do Sul.

O índice CDD (dias secos consecutivos) apresentou tendência de diminuição para a maior parte das estações. Apenas duas estações (Agrolândia e Vidal) apresentaram valores positivos e uma única estação (Ituporanga $\mathrm{Sul}$ ) apresentou valor neutro. Esses valores de CDD refletiram nos resultados do índice CWD (dias úmidos consecutivos) com ligeira estabilidade, assim como nos valores referentes ao índice SDII (índice de intensidade diária simples). Os três índices apresentaram valores muito próximos de zero, variando entre valores positivos ou negativos, restritos à unidade centesimal (Tabela 2).

Em síntese, embora os resultados dos índices sejam baixos para aferir quaisquer variabilidades nas chuvas da região, é possível identificar uma pequena tendência de diminuição dos dias secos e, consequentemente, um relativo aumento dos dias úmidos.

Tabela 1. Registro de inundações, período de 1983-2015. 


\begin{tabular}{c|c|c|c|c}
\hline Ano & Mês & Precipitação $(\mathrm{mm})$ & Cota $(\mathrm{m})$ & Dias de chuva \\
\hline 1983 & Julho & 606,7 & 13,58 & 20 \\
\hline 1984 & Agosto & 324,6 & 12,8 & 14 \\
\hline 1992 & Maio & 295,1 & 8,52 & 12 \\
\hline 1997 & Fevereiro & 297 & 8,72 & 16 \\
\hline 1997 & Outubro & 247 & 7,33 & 22 \\
\hline 1998 & Abril & 198 & 7,96 & 10 \\
\hline 1999 & Julho & 183 & 7 & 15 \\
\hline 2001 & Outubro & 159,5 & 9,1 & 12 \\
\hline 2002 & Novembro & 225,3 & 7,14 & 14 \\
\hline 2004 & Setembro & 110,3 & 6,89 & 4 \\
\hline 2005 & Maio & 187,5 & 6,87 & 9 \\
\hline 2005 & Setembro & 234,3 & 7,64 & 19 \\
\hline 2007 & Novembro & 142,9 & 6,76 & 12 \\
\hline 2009 & Setembro & 292 & 8,55 & 13 \\
\hline 2010 & Abril & 254 & 7,53 & 7 \\
\hline 2011 & Fevereiro & 211,5 & 6,31 & 18 \\
\hline 2011 & Julho & 72,2 & 6,5 & 3 \\
\hline 2011 & Agosto & 143,4 & 8,83 & 5 \\
\hline 2011 & Agosto & 344,2 & 8,76 & 17 \\
\hline 2011 & Setembro & 300,6 & 12,96 & 6 \\
\hline 2013 & Agosto & 55 & 6,17 & 2 \\
\hline 2013 & Setembro & 131,1 & 10,39 & 4 \\
\hline 2014 & Janeiro & 95,5 & 6,24 & 3 \\
\hline 2014 & Junho & 147,5 & 7,76 & 4 \\
\hline 2014 & Junho & 152,6 & 9,42 & 6 \\
\hline 2014 & Outubro & 147,4 & 8,16 & 8 \\
\hline 2015 & Junho & 87,2 & 6,15 & 4 \\
\hline 2015 & Setembro & 70,4 & 7,23 & 2 \\
\hline 2015 & Outubro & 44 & 7,24 & 2 \\
\hline 2015 & Outubro & 41 & 8,75 & 2 \\
\hline 2015 & Outubro & 109 & 10,71 & 2 \\
\hline & & & \\
\hline & & & \\
\hline
\end{tabular}

Fonte: Defesa Civil de Rio do Sul, 2016.

Os índices Rx1dia, Rx5dias e Rx8dias apresentaram tendências de dias consecutivos de precipitação de acordo com seus respectivos dias. Identifica-se, de modo geral, tendência de aumento, principalmente no que se refere aos Rx5dias e Rx8dias consecutivos, que apresentaram maiores valores em seus índices, sugerindo maiores registros de precipitação no intervalo semanal. Esse resultado é corroborado pelo índice de PRCTOT (total anual de dias de chuva), que apresentou, apenas para estação de Vidal Ramos, diminuição das precipitações. As demais localidades apresentaram tendência positiva, indicando aumento nos totais pluviais. Em suma, fica evidente que há uma tendência de aumento nos registros de precipitação.

Tabela 2. Índices de tendências de variabilidade das precipitações pluviais.

\begin{tabular}{|c|c|c|c|c|c|c|c|c|c|c|c|}
\hline Estações & $C D D$ & $C W D$ & SDII & Rx1day & $R \times 5$ day & $R \times 8 d a y$ & PRCPTOT & $\mathrm{r} 10 \mathrm{~mm}$ & $\mathrm{r} 20 \mathrm{~mm}$ & $R 95 p$ & $R 99 p$ \\
\hline Agrolândia & 0,04 & $-0,03$ & 0,12 & $-0,15$ & $-1,39$ & $-2,19$ & 2,23 & 0,08 & 0,08 & 1,91 & 0,06 \\
\hline Ituporanga & $-0,07$ & 0,00 & 0,00 & 0,22 & 0,37 & 0,46 & 3,04 & 0,01 & 0,04 & 2,26 & 1,12 \\
\hline Ituporanga Sul & 0,00 & 0,02 & $-0,01$ & 0,27 & 0,39 & 0,44 & 5,12 & 0,12 & 0,10 & $-0,49$ & 1,22 \\
\hline Leoberto & $-0,03$ & $-0,02$ & 0,01 & $-0,14$ & 0,19 & $-0,01$ & 5,70 & 0,17 & 0,10 & 1,85 & 1,52 \\
\hline Lomba & $-0,11$ & 0,01 & $-0,06$ & $-0,07$ & 0,23 & 0,09 & 0,73 & $-0,08$ & 0,04 & 0,32 & 0,08 \\
\hline Ponta Alta & $-0,05$ & $-0,04$ & 0,04 & 0,31 & 0,53 & 0,57 & 8,01 & 0,18 & 0,18 & 2,40 & 0,96 \\
\hline Pouso & $-0,03$ & 0,00 & 0,03 & 0,28 & 0,57 & 0,79 & 6,67 & 0,17 & 0,10 & 2,79 & 1,16 \\
\hline Rio Antinhas & $-0,04$ & 0,00 & $-0,04$ & $-0,10$ & $-0,10$ & $-0,01$ & 7,83 & 0,22 & 0,15 & 1,24 & 0,31 \\
\hline Rio do Sul & $-0,05$ & 0,02 & 0,00 & 0,12 & 0,11 & 0,15 & 5,14 & 0,11 & 0,10 & 2,32 & 1,11 \\
\hline Saltinho & $-0,09$ & 0,00 & 0,01 & 0,12 & 0,37 & 0,02 & 4,37 & 0,10 & 0,10 & 1,84 & $-0,72$ \\
\hline Taio & $-0,10$ & 0,01 & 0,03 & 0,27 & 0,41 & 0,51 & 5,90 & 0,14 & 0,14 & 2,79 & 0,93 \\
\hline Trombudo & $-0,06$ & 0,02 & $-0,01$ & 0,04 & 0,23 & 0,26 & 4,52 & 0,12 & 0,08 & 1,66 & 0,49 \\
\hline Vidal & 0,16 & $-0,07$ & 0,08 & 0,38 & 0,68 & 0,55 & $-2,34$ & $-0,10$ & 0,14 & 4,88 & 1,39 \\
\hline Vila Canoas & $-0,18$ & 0,05 & $-0,07$ & 0,37 & 0,59 & 0,65 & 6,99 & 0,08 & 0,08 & 2,29 & 1,35 \\
\hline
\end{tabular}

Legenda: Cinza claro: valores negativos, tendência de diminuição; Cinza escuro: valores positivos, tendência de aumento; Brancos: valor zero, sem tendência; Valores em negrito $p=0,05$.

Esse aumento dos totais pluviais é representado, principalmente, com precipitação 
acima de $20 \mathrm{~mm}$ quando comparamos os índices $\mathrm{R} 10 \mathrm{~mm}$ e R20mm, resultando em episódios de extremos e muito extremos de precipitação, conforme apresentados nos índices R95p e R99p, que se revelaram com tendências positivas, com maiores valores para os episódios extremos de precipitação (Tabela 2).

Portanto, a análise dos índices revelou que há uma tendência de aumento da intensidade diária das precipitações (SDII) associada, principalmente, ao aumento dos dias consecutivos de chuva (Rx1dia, Rx5dias e Rx8dias). Dessa maneira, identificou-se que, para a região da microbacia de Rio do Sul, é possível afirmar que há possibilidade de aumento do total anual das precipitações pluviais (PRCTOT), indicando que essas chuvas não estão associadas a uma distribuição contínua ao logo dos dias (R10mm, R20mm, Rx1dia, Rx5dias e Rx8dias), mas concentradas na ocorrência de aumento dos eventos extremos (R95p e 99p).

Faz-se necessário destacar que, dos valores apresentados na Tabela 2, alguns índices não apresentaram significância estatística, ou seja, com valores de $p=0,05$. No entanto, os valores dos índices não inviabilizam os resultados encontrados, uma vez que se tratam de tendências e não de um estudo de projeções futuras das precipitações pluviais. E, ainda, por se tratar de um elemento de extrema dinamicidade, como são as precipitações pluviais, esperar que análises estatísticas padronizem um elemento de natureza dinâmica é praticamente impossível devido aos tantos outros fatores que fazem parte do processo de origem e distribuição das chuvas.

Embora o fenômeno das inundações seja entendido não pela única ocorrência de precipitações, mas por toda uma série de fatores que contribuem para deflagrar um evento, as precipitações constituem um dos principais elementos a serem considerados, uma vez que repercutirão no aumento da vazão do rio. Portanto, faz-se necessário compreender a variabilidade das chuvas e suas possíveis tendências de ocorrência (quantidade e períodos de concentração).

Como resultado da análise empregada, é possível afirmar que há uma tendência de aumento das precipitações, ocorrendo de forma concentrada na propagação de eventos extremos na sub-bacia que integra o município de Rio do Sul. Esse resultado é importante, pois apenas as precipitações pluviais, em si, já se configuram em maior ocorrência de vazão dos rios Itajaí Oeste e Itajaí do Sul. Desse modo, verifica-se que, nos últimos anos, as chuvas apresentaram aumento no acumulado de sua totalidade (PRCTOT), intensidade e ocorrência de extremos (índices R95p e R99p).

Por fim, novas investigações estão sendo desenvolvidas na área de estudo, uma vez que os resultados aqui apresentados indicam que a vulnerabilidade que existente nos centros urbanos, no que diz respeito à precipitação extrema, aponta a necessidade urgente de melhorar as infraestruturas e a necessidade de investir em sistemas de observação meteorológica, no processamento e disseminação de informação, na atualização constante da infraestrutura e no aumento da pesquisa em previsões meteorológicas e climáticas. $\mathrm{O}$ aumento das precipitações pluviométricas e os eventos de chuvas pesadas e extremas sobre partes dos eventos de chuva em Rio do Sul, combinados com outros fatores, reforçam a previsão de que novos eventos de inundação e possíveis deslizamentos de terra poderão ocorrer na região no futuro.

\section{Conclusão}

Partindo do pressuposto que a Ciência Geográfica estuda as relações entre a sociedade e a natureza e é, portanto, dotada para compreender os problemas socionaturais, o presente artigo buscou contribuir com a discussão sobre a análise das precipitações pluviais, da qual se faz necessário o conhecimento de sua dinâmica envolvendo a sazonalidade, ocorrência e tendência para compreender como estão associadas à ocorrência de episódios de inundações no município de Rio do Sul.

Os resultados evidenciaram que as chuvas apresentaram, ao longo das últimas três décadas, aumento nos seus registros totais, assim como maior ocorrência de episódios extremos. Além disso, a estação de inverno ficou caracterizada com os maiores registros de inundações que ocorrem na área de estudo.

Muito embora os desastres por inundações são associados a fenômenos pluviométricos extremos e relacionados às características do espaço como, por exemplo, as formas de relevo, a rede de drenagem e o uso da terra, as alterações e modificações que o homem exerce nos diferentes espaços, o uso e ocupação irregular nas planícies e margens de cursos d'água, alterações na dinâmica natural das bacias hidrográficas, impermeabilização do solo, entre outros, aqueles resultam na ocorrência de fenômenos que causam prejuízos econômicos e perdas e danos sociais à população (Murara, 2015).

Portanto, enquanto produto das ações antrópicas, os espaços urbanos se configuram pelas relações e interações entre as esferas sociais e naturais. As cidades podem ser encaradas como 
produtos das transformações que resultam em novas formas socionaturais, e as relações e interações do homem com a natureza repercutirão em novos objetos socionaturais (Swyngedouw, 2009). Nesse novo ambiente, devido às características físicas do seu sítio urbano, os fenômenos de inundações passam a ser recorrentes e cada vez mais impactantes nas populações.

Diante do exposto, mostra-se evidente que a construção do espaço associada à maior ocorrência de precipitações pluviais e eventos extremos de chuvas resultou e, possivelmente, resultará na ocorrência cada vez maior de eventos de inundações em Rio do Sul e, também, na mesorregião do Vale do Itajaí, visto que a área de estudo aqui apresentada se caracteriza pela porção a montante da bacia.

\section{Agradecimentos}

Deixo aqui o registro e o eterno agradecimento da orientação da Prof. ${ }^{a}$ Dr. ${ }^{a}$ Magaly Mendonça que, desde o meu Mestrado (2010) até o período de finalização do meu Doutorado (2016) participou intensamente do meu crescimento intelectual e profissional, sou fui feliz pela oportunidade de trabalho, pesquisa e nossa relação de amizade, afetividades e muitas festividades que vivemos. Agradeço a organização da Associação Brasileira de Climatologia - ABCLIMA, pelo convite para publicação desta edição especial.

\section{Referências}

Acquaotta, F., Fratianni, S., 2014. The importance of the quality and reliability of the historical time series for the study of climate change. In: Revista Brasileira de Climatologia 14, 20-38.

Acquaotta, F., Venema, V., Fratianni, S., 2015a. Assessment of parallel precipitation measurements networks in Piedmont, Italy. In: International Journal of Climatology 14, 39633974.

Acquaotta, F., Garzena, D., Guenzi, D., et al., 2015b. Co.Rain - Comparing Series of Rain. CoRain v1.0 [Data set] Zenodo. Disponível: http://doi.org/10.5281/zenodo.58478.

Armond, N.B., Sant'anna Neto, J.L. 2017. Entre eventos e episódios: ritmo climático e excepcionalidades para uma abordagem geográfica do clima no município do Rio de Janeiro. Revista Brasileira de Climatologia 20, 5-28.

Barros, V.R., Grimm, A.M., Doyle, E.M.E., 2002. Relationship between temperature and circulation in Southeastern South America and its influence from $\mathrm{El}$ Niño and La Niña events. Journal of the Meteorological Society of Japan 80, 21-32.
Biancotti, A., Destefanis, E., Fratianni, S., Masciocco, L., 2005. On precipitation and hydrology of Susa Valley (Western Alps). In: Geografia Fisica e Dinamica del Quaternario. suppl. VII: 51-58.

EPAGRI/CIRAM. Empresa de Pesquisa Agropecuária e Extensão Rural de Santa Catarina. Centro de Informações de Recursos Ambientais e de Hidrometeorologia de Santa Catarina. Disponível: <http://www.ciram.com.br>. Acesso: 13 jan. 2016.

Fraga, N.C., 2005. Vale das Águas Revoltas: sociedade, natureza e políticas públicas antienchentes no Vale do Itajaí, (SC) no século XX. Asselvi, Indaial, SC.

Frank, B., 1995. Uma abordagem para o gerenciamento ambiental da bacia Hidrográfica do rio Itajaí, com ênfase no problema das enchentes. Tese (Doutorado) Florianópolis, UFSC.

Frank, B. et al., 1997. Procedimentos adotados na criação do Comitê do Itajaí - Santa Catarina. In: Simpósio da Associação Brasileira de Recursos Hídricos, Vitória: Anais...

Frank, B., 1999. Uma abordagem para gestão ambiental da Bacia do Rio Itajaí, com ênfase para os problemas das cheias. Revista de Estudos Ambientais 1, 5-18.

Frank, B., Pinheiro, A. (Org.), (2003). Enchentes na Bacia do Rio Itajaí: 20 anos de experiências. FURB, Blumenau.

Frank, B., Savegnani, L. (org.), 2009. Desastre de 2008 no Vale do Itajaí. Água, Gente e Política. Agência de Água do Vale do Itajaí, Blumenau.

Grimm, A.M., 2009. Clima da Região Sul do Brasil. In: Cavalcanti, I.F.A., Ferreira, N.J., Silva, M.G.A., Silva Dias, M.A.F. (orgs), Tempo e Clima no Brasil. Oficina de Textos, São Paulo.

Herrmann, M.L., Kobiyama, M., Marcelino, E.V., 2007. Inundação Gradual. In: Herrmann, M.L.P. (org)., Atlas de desastres naturais do estado de Santa Catarina. IOESC Florianópolis.

Herrmann, M.L.P. (org)., 2014. Atlas de Desastres Naturais do Estado de Santa Catarina: período de 1980 a 2010. $2^{\text {a }}$ ed. atual. e rev. IHGSC/Cadernos Geográficos, Florianópolis.

Hillesheim, W.T., Neves, L.O., 2015. Análise frequencial e distribuição das chuvas na região de Rio do Sul/SC. In: Ciência e Natura, Santa Maria, v. 37 Ed. Especial SIC, p.119-124.

IBGE. Instituto Brasileiro de Geografia e Estatística. Censo Demográfico 1991/2010. 2010. Disponível: <http://www.ibge.gov.br>. Acesso: 23 jan. 2014. 
IPCC., 2012. Intergovernmental Panel on Climate Change. Managing the Risks of Extreme Events and Disasters to Advance Climate Change Adaptation. A Special Report of Working Groups I and II of the Intergovernmental Panel on Climate Change [Field, C.B., V. Barros, T.F. Stocker, D. Qin, D.J. Dokken, K.L. Ebi, M.D. Mastrandrea, K.J. Mach, G.-K. Plattner, S.K. Allen, M. Tignor, and P.M. Midgley (eds.)]. Cambridge University Press, Cambridge, UK, and New York, NY, USA, 582 pp.

IPCC., 2014. Intergovernmental Panel on Climate Change. Climate Change 2014: Impacts, Adaptation, and Vulnerability. Part A: Global and Sectoral Aspects. Contribution of Working Group II to the Fifth Assessment Report of the Intergovernmental Panel on Climate Change [Field, C.B., V.R. Barros, D.J. Dokken, K.J. Mach, M.D. Mastrandrea, T.E. Bilir, M. Chatterjee, K.L. Ebi, Y.O. Estrada, R.C. Genova, B. Girma, E.S. Kissel, A.N. Levy, S. MacCracken, P.R. Mastrandrea, and L.L. White (eds.)]. Cambridge University Press, Cambridge, United Kingdom and New York, NY, USA, p. 1132.

Klein Tank, A.M.G., Können, G.P., 2003. Trends in indices of daily temperature and precipitation extremes in Europe, 1946-99. International Journal of Climatology. 16, 3665-3680.

Klein Tank, A.M.G., Wijngaard, J.B., Können, G.P.. 2002. Daily surface air temperature and precipitation dataset 1901-1999 for European Climate Assessment (ECA). International Journal of Climatology 22, 1441-1453.

Mittersteins, M.R., Severo, D.L., 2007. Análise de variabilidade intrasazonal e interanual da precipitação no Vale do Itajaí com a transformada de ondaletas. In: Dynamis revista tecno-científica 13, 01-10.

Marengo, J.A., Nobre, C.A., 2009. Clima da Região Amazônica. In: Cavalcanti, I.F.A.; Ferreira, N.J.; Da Silva, M.G.A.J.; Silva Dias, M.A.F. (Orgs.). Tempo e Clima no Brasil. Oficina de Textos, São Paulo.

Monteiro, C.A. de F., 1968. Clima. In: Grande Região Sul. Geografia do Brasil, vol IV. Tomo I, $2^{\mathrm{a}}$ ed. Cap III, IBGE, Rio de Janeiro. p.115158.

Monteiro, C.A.F., 1976. Teoria e Clima Urbano. São Paulo: Universidade de São Paulo, Instituto de Geografia.

Monteiro, M., Furtado. S.M., 1995. O Clima do Trecho Florianópolis - Porto Alegre: Uma abordagem Dinâmica. Revista GEOSUL. Florianópolis, nº 19/20.

Monteiro, M., 2001. Caracterização climática do estado de Santa Catarina: uma abordagem dos principais sistemas atmosféricos que atuam durante o ano. Revista GEOSUL. Florianópolis, v.16, n.31, p 69-78.

Monteiro, M., Mendonça, M., 2014. Dinâmica Atmosférica no Estado de Santa Catarina. In: Herrmann, M.L.P. (org). Atlas de Desastres Naturais do Estado de Santa Catarina: período de 1980 a 2010. $2^{\mathrm{a}}$ ed. atual. e rev. IHGSC/Cadernos Geográficos, Florianópolis.

Murara, P., 2015. Inundações: desastres naturais? Revista Discente Expressões Geográficas. V.1, p. 158-172.

Murara, P., 2016. Adaptação humanas às inundações em áreas urbanas em Rio do Sul, Santa Catarina. Tese (Doutorado), Florianópolis, UFSC.

Murara, P., Ikefuti, P.V., 2017. Análise das precipitações pluviais em Rio do Sul, Santa Catarina. Geografia ensino \& pesquisa, v. 21, p. $186,2017$.

Nery, J., 2005. Dinâmica Climática da Região Sul do Brasil. Revista Brasileira de Climatologia. DOI: http://dx.doi.org/10.5380/abclima.v1i1.25233

Nimer, E., 1979. Climatologia do Brasil. Instituto Brasileiro de Geografia e Estatística, Rio de Janeiro, RJ. p.421.

Rodrigues, M.L.G., Franco, D., Sugahara, S., 2004. Climatologia de frentes frias no litoral de Santa Catarina. Revista Brasileira de Geofísica 22, 135-151.

Swyngedouw, E., 2009. A cidade como um híbrido: natureza, sociedade e "urbanizaçãociborgue". In: Ascelrad, H. (org.) A duração das cidades: sustentabilidade e risco nas políticas urbanas. $2^{a}$ ed. Lamparina, Rio de Janeiro.

Wang, X., Chen, H., Wu, Y., 2010. New techniques for the detection and adjustment of shifts in daily precipitation data series. Journal of Applied Meteorology and Climatology 49, 2416-2436. 